\title{
A Systematic Review of Herbal Medicine in the Treatment of Cirrhotic Ascites
}

\author{
Seungmo Kim, Yuri Lee, Nakyung Cho, Hongsik Choi, Kyungsoon Kim* \\ Department of Korean Internal Medicine of Hepatology, College of Korean Medicine, Daegu Haany University
}

\begin{abstract}
Objectives: The purpose of this study was to investigate the trend in the research on cirrhotic ascites using $t$ herbal medicine.

Methods: This review was conducted using six electronic databases(NDSL, KMBASE, Koreantk, KISS, KISTI, KoreaMed) with no restriction in year. The search term was 'liver cirrhosis', 'ascites', or 'cirrhotic ascites', 'herbal medicine', 'traditional Chinese medicine', and 'randomized clinical trial', and there was no restriction in year. The searched studies were analyzed according to the type of research.

Results: After scanning the titles and abstracts, 13 articles were ultimately included. Of the outcome measures of 13 studies, effective rate, liver function test, and ascites regression time were included in the meta-analysis, which showed that the effective rate of herbal medicine-supportive treatment combination therapy was 1.27 times higher than that of supportive treatment alone, and the difference was statistically significant.

Conclusions: We analyzed the trends of cirrhotic ascites treatment in herbal medicine through this review. It is necessary to conduct further studies, such as well-designed clinical trials based on the results from experimental research.
\end{abstract}

$\overline{K e y}$ Words : cirrhotic ascites, herbal medicine, systematic review, meta analysis

\section{Introduction}

According to the Statistics Korea's 2017 Causes of Death Statistics, mortality rate for liver disease was 13.3 deaths per 100,000 population, making it the eighth leading cause of death ${ }^{1)}$. Along with liver cancer, liver cirrhosis is one of the major causes of death in patients with chronic liver disease and the end-stage of all chronic liver diseases. Pathological characteristics of liver cirrhosis are the formation of regenerative nodules and extensive fibrosis, resulting in reduction in liver parenchyma and altered liver function and blood flow, which in turn can lead to ascites, variceal bleeding, jaundice, coagulopathy, and hepatic encephalopathy ${ }^{2}$. Of these complications, ascites causes abdominal bloating and systemic discomfort due to increased weight and abdominal circumference and accompanying peripheral edema. In addition, patients complain of reduced meal size and dyspnea from abdominal organ compression, decreasing patients' quality of life, which can

\footnotetext{
- Received : 28 September 2021

- Revised : 1 November 2021

- Accepted : 5 November 2021

- Correspondence to : Kyungsoon Kim

165, Sang-dong, Suseong-gu, Daegu, Department of Korean Internal Medicine of Hepatology, College of Korean Medicine, Daegu Haany University

Tel : +82-53-770-2082, Fax : +82-53-770-2055, E-mail : occ@dhu.ac.kr
} 
lead to mental pain and depression ${ }^{2-4)}$. To treat ascites in liver cirrhosis, nutritional therapy, restricted sodium intake, pharmacological treatment, such as diuretics, and abdominal paracentesis are used in modern medicine. ${ }^{5)}$ However, prognosis for patients with decompensated cirrhosis and ascites is poor, with one- and two-year survival rate of only $60 \%$ and $45 \%$, respectively ${ }^{6)}$.

In Korean medicine, jaundice, distention and fullness, aggregation-accumulation, and hypochondriac pain are considered to be part of liver diseases, and ascites, in particular, fall under distention and fullness ${ }^{7)}$. Study results related to the therapeutic effect of Korean medicine on liver cirrhosis have been continuously reported through clinical trials $^{8-11)}$. However, in the past 10 years in Korea, there have been no reports of clinical trials related to use of herbal medicine in the treatment of ascites in liver cirrhosis. Therefore, the authors conducted a systematic review of Korean and international clinical trials that provided herbal medicine treatment in patients with cirrhotic ascites in order to contribute to the vitalization of herbal medicine use in the treatment of cirrhotic ascites. Here, we report the objective evidence drawn from the review.

\section{Participants and methods}

\section{Participants}

Herbal medicine articles that investigated the therapeutic effect of herbal medicine in patients with liver cirrhosis and ascites were included. The PICO-SD (participants, intervention, comparison, outcome, study design) format was followed for the systematic review.
1) Participants: Patients with cirrhotic ascites

2) Intervention: Herbal medicine treatment (oral herbal preparation prescribed by a doctor)

3) Comparison: no restriction on control group

4) Outcome: no restriction on outcomes

5) Study design: randomized controlled trials (RCT)

\section{Methods}

1) Database selection and literature search

The Korean literature databases of National Digital Science Library (http://www.ndsl.kr), Korean Medical Database http://kmbase.medric.or.kr), Korean studies Information Service System (http://kiss.kstudy.com), Society KISTI (http://society. kisti.re.kr), KoreaMed (http://www.koreamed.org), Korean Traditional Knowledge Portal (http://www. koreantk.com), and Korea Institute of Oriental Medicine (http://oasis.kiom.re.kr) were searched to identify Korean articles. The keywords used in the Korean search engines were 'liver cirrhosis', 'ascites', or 'cirrhotic ascites', 'herbal medicine', and 'randomized controlled trial'.

The databases of PubMed (http://www.ncbi. nlm.nih.gov/pubmed/), EMBASE (http://www. embase.com), Cochrane CENTRAL (http://www. thecochranelibrary.com), and CNKI (http://www. cnki.net were searched to identify international articles, and the keywords used in the search engines were 'liver cirrhosis' or 'ascites', 'herbal medicine' or 'traditional Chinese medicine', and 'randomized controlled trial'

\section{2) Study selection}

Two investigators (LYR and CNK) independently searched and selected the studies. The identified 


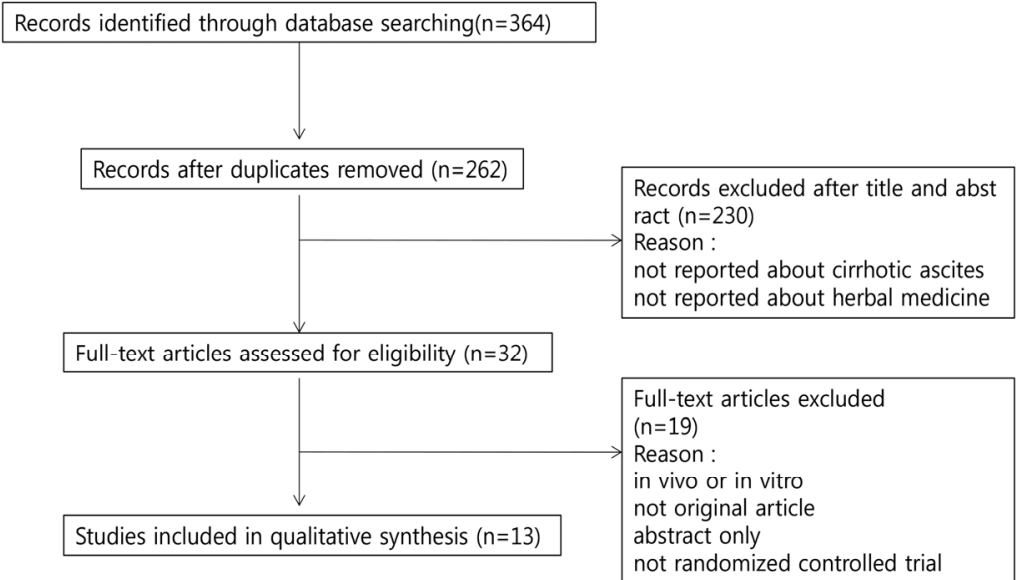

Fig. 1. Flow diagram of the selection process

studies were combined, and duplicates were removed. The titles and abstracts of studies were initially screened based on the inclusion and exclusion criteria, and only RCTs that used herbal medicine treatment for the purpose of treating cirrhotic ascites were selected through full-text review. Any disagreements between the two investigators were resolved by majority vote after review by a third investigator (KKS).

The search was conducted between March 14 and 16, 2019 for studies published up to February 2019 without language restriction. Of the identified articles, RCTs that provided oral herbal medicine prescription in patients with cirrhotic ascites were selected, and studies were excluded if they were non-clinical in vivo or in vitro studies, not an original publication, reported as abstracts only, or provided herbal medicine treatment as an enema or a patch were excluded (Fig. 1).

3) Data analysis

Following a full-text review of the selected studies, data on publication year, number of participants, treatment method and length of intervention and control groups, assessment tools, therapeutic effect, and incidence of adverse events of each study were extracted. Any disagreements on data extraction were resolved by consultation with a third investigator.

\section{4) Risk of bias assessment}

The Cochrane's Risk of Bias (RoB) tool was used as this systematic review only included RCTs. This tool assesses bias across seven domains: random sequence generation, allocation concealment, blinding of participants and personnel, blinding of outcome assessors, handling of incomplete outcome data, selective outcome reporting, and other sources of bias that compromise the validity. For detailed criteria of each domain, NECA's systematic review manual ${ }^{12)}$ was used.

5) Publication bias

Publication bias is a type of reporting bias that 
occurs when the likelihood of a study being published is associated with statistical significance of study's outcome. It is commonly assessed using a funnel plot, and Egger's regression test was performed as a statistical test.

\section{6) Meta-analysis}

Statistical analysis of the studies included in the systematic review was performed using the Cochrane Collaboration's RevMan (Review Manager) version 5.3. To measure effect size, risk ratio (RR) with two-sided 95\% confidence interval (CI) was calculated for dichotomous outcome variables mean difference (MD) with 95\% CI was calculated for continuous outcome variables. After assessing heterogeneity using Higgins $\mathrm{I}^{2)}$ test, the summary statistics from each study were combined for meta-analysis using both fixed-effects and random-effects models.

\section{Results}

\section{Data extraction}

After removing duplicates, a total of 262 studies were identified by the literature search of a total of 11 databases conducted between March 14 to 16, 2019. After scanning the titles and abstracts, we excluded 230 articles that were not RCTs and not relevant to cirrhotic ascites and oral herbal medicine treatment. Following full-text review of the 32 articles initially identified, 13 $\operatorname{articles}^{13-25)}$ that met inclusion criteria were ultimately included.

\section{Data analysis}
1) Study design

The thirteen studies ultimately selected were RCTs conducted in China and Iran between 2005 and 2018. These articles investigated the effects of oral herbal medicine on cirrhotic ascites when used as a stand-alone therapy or in combination with acupuncture and western medicine (Table 1).

2) Intervention and control groups

(1) Duration of treatment

Duration of medicine administration varied by studies, ranging from 21 days to 6 months, with a mean duration of 99.7 days. Duration of medicine administration was 3 months in five studies $^{14,16,18,22,24)}$, 6 months in two studies ${ }^{13,15)}, 5$ months in two studies ${ }^{20-21)}$, and 2 months in two studies $^{17,25)}$ (Table 1).

(2) Intervention group design

Of the selected studies, 10 studies $^{13-16,18-20,22,24-25)}$ provided herbal medicine treatment in combination with supportive treatment of western medicine and compared its effect with that of supportive treatment alone. One study ${ }^{21)}$ compared herbal medicine stand-alone therapy with supportive treatment. Two studies ${ }^{17,23)}$ provided additional herbal medicine; one study provided herbal medicine, acupuncture, and supportive treatment and compared it with supportive treatment ${ }^{17)}$, and one study provided herbal medicine in combination with moxibustiom and supportive treatment and compared it with supportive treatment ${ }^{23)}$. The herbal preparations used for intervention were as follows (Table 2).

(3) Control group design

Control groups in all studies received supportive 


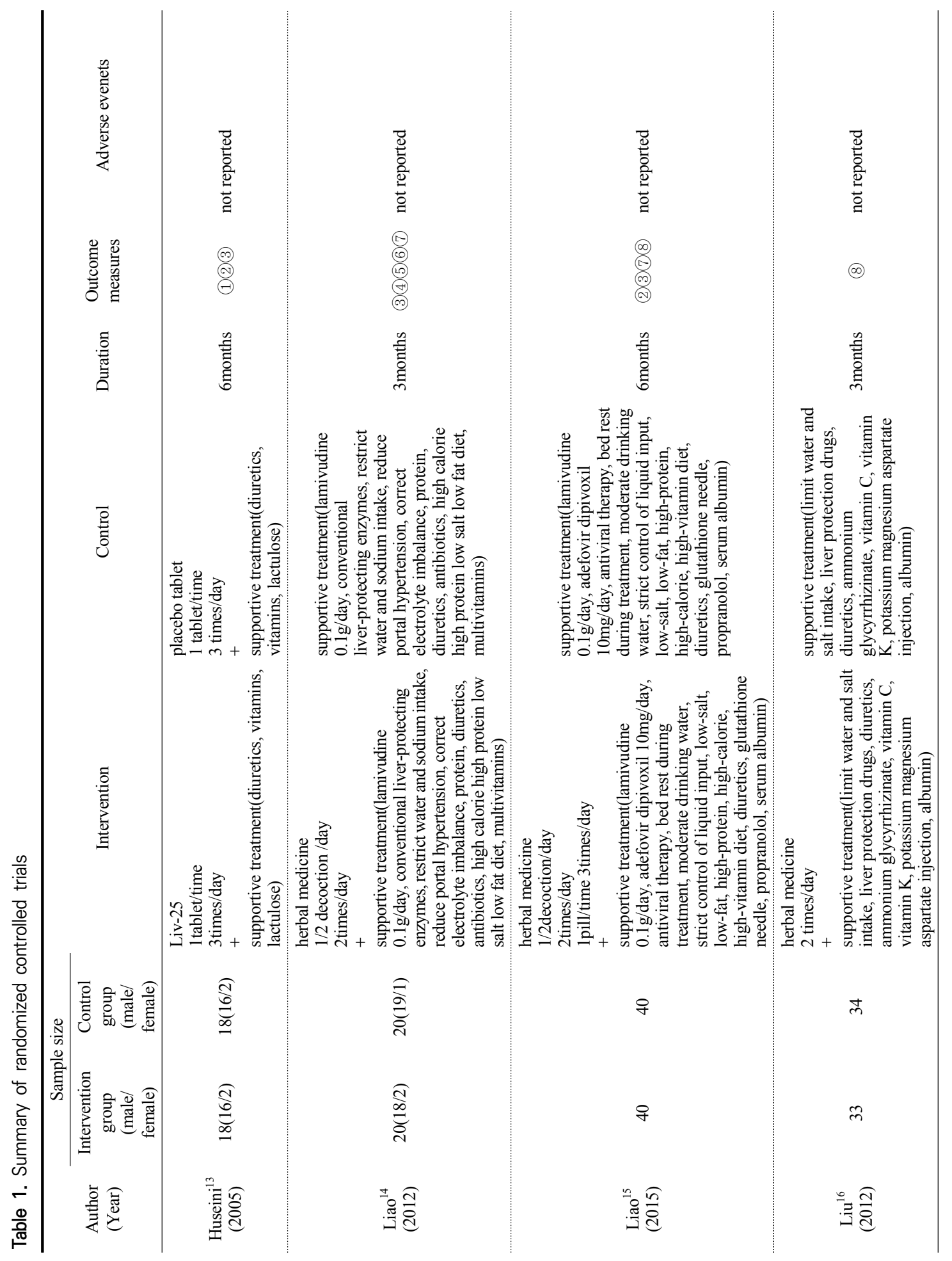




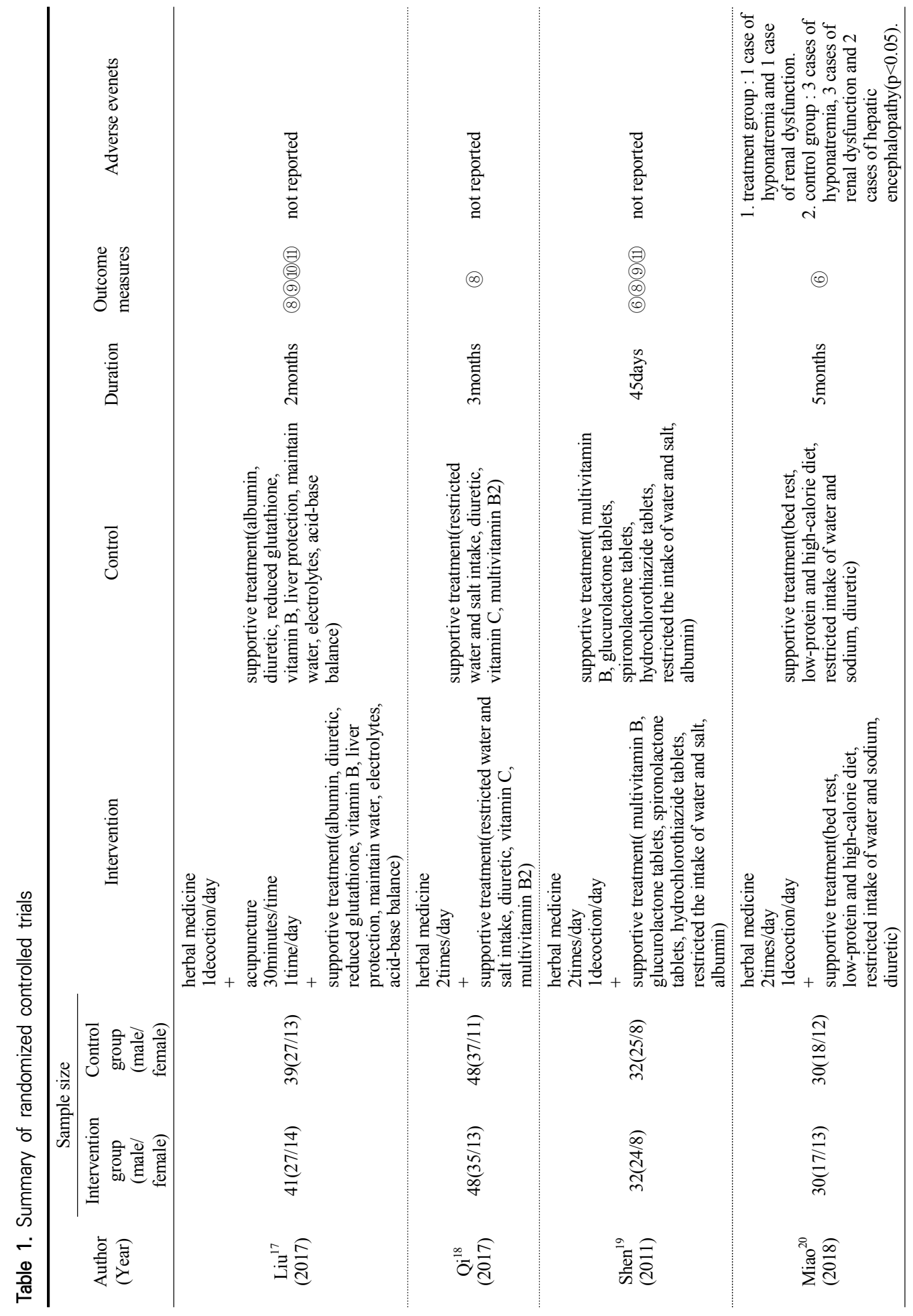


(674) Journal of Korean Medicine 2021;42(4)

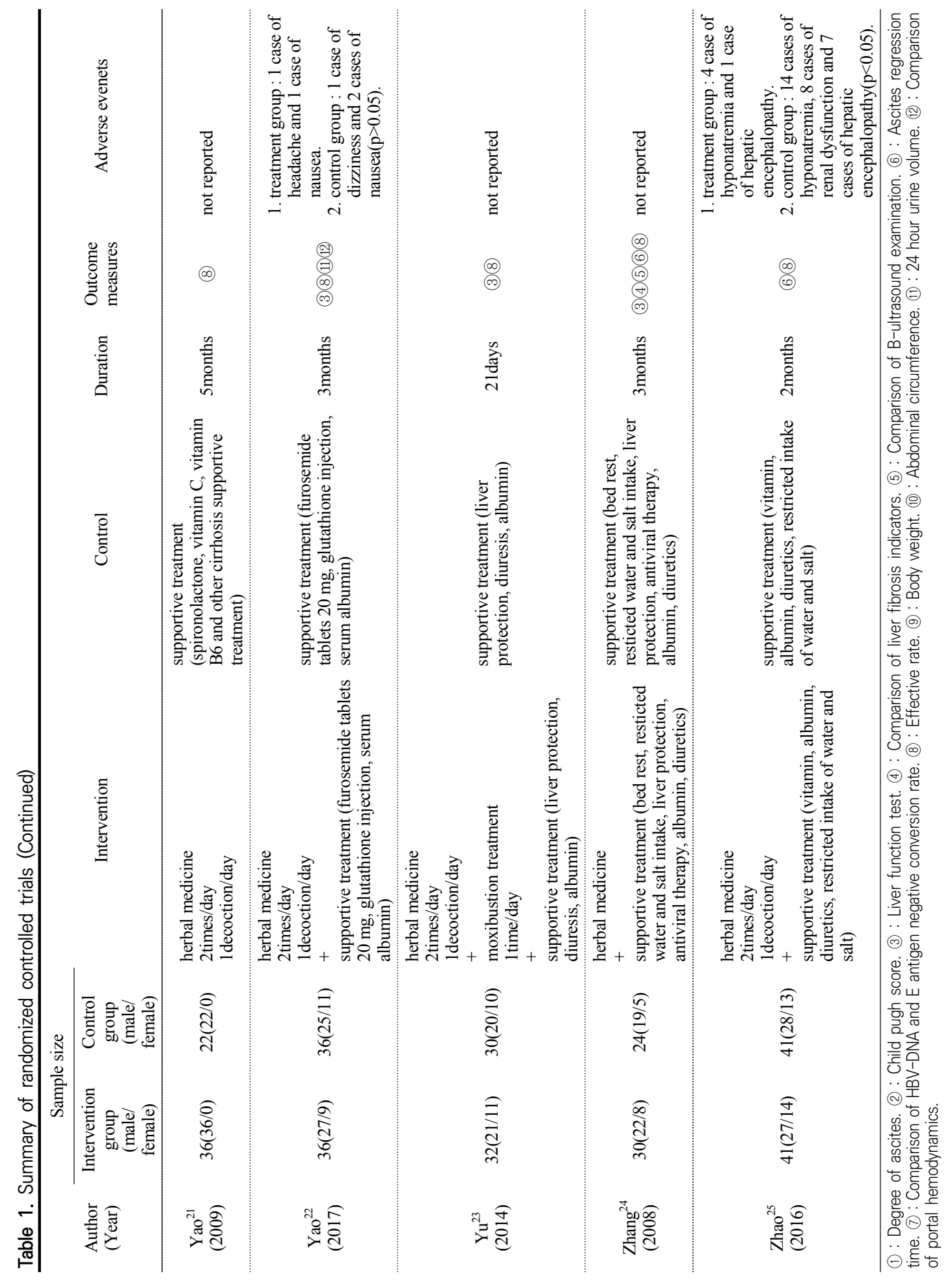




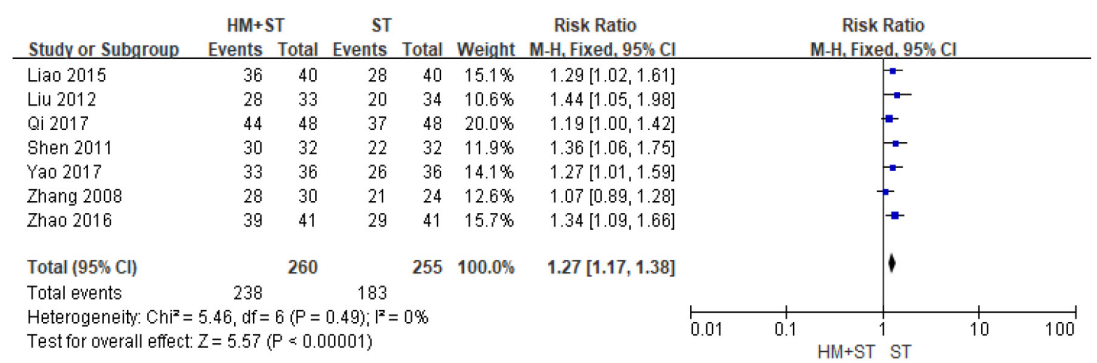

Fig.2. Results of Meta-analysis for the Effective Rate(HM+ST vs ST)

Abbreviations: HM, herbal medicine; ST, supportive treatment

treatment of western medicine, and, with the exception of one study ${ }^{21)}$, intervention groups also received the same supportive treatment. Studies included various supportive treatments, including bed rest, restricted water and salt intake, albumin, and diuretics, and detailed description is presented in table 1.

\section{3) Outcome measures}

Outcome measures used in the selected studies were effective rate, ascites regression time, liver function test, 24 hour urine volume, and Child -Pugh score. Of these, effective rate was used in 10 studies $^{15-19,21-25)}$, liver function test was used in six studies ${ }^{13-15.22-24)}$, and ascites regression time was used in five studies ${ }^{14,19-20,24-25)}$ as outcome measures. Of the outcome measures, effective rate, liver function test, and ascites regression time were included in the meta-analysis.

\section{4) Therapeutic effect}

Of the selected studies, 10 studies that compared herbal medicine-supportive treatment combination therapy with supportive treatment stand-alone therapy ${ }^{13-16,18-20,22,24-25)}$ were included in the meta-analysis.

\section{(1) Effective rate}

Effective rate of herbal medicine-supportive treatment combination therapy was 1.27 times higher than that of the supportive treatment stand-alone therapy, indicating herbal medicine -supportive treatment combination therapy is significantly more effective in treating cirrhotic ascites. A low degree of heterogeneity was observed across the studies (Risk Ratio $=1.27$, 95\% CI: 1.17 to $1.38, \mathrm{p}<0.001, \mathrm{I}^{2}=0 \%$, Fig. 2 )

\section{(2) Liver function test}

A subgroup analysis was performed to compare liver function test of herbal medicine-supportive treatment combination therapy and supportive treatment stand-alone therapy. The intervention group showed significant effect than the control group and a high degree of heterogeneity of $98 \%$ was observed across the studies (Mean Difference $=-11.39,95 \%$ CI: -15.08 to $-7.69, \mathrm{p}<0.001, \mathrm{I}^{2}=98 \%$, Fig. 3).

(3) Ascites regression time

Although not statistically significant, ascites regression time of the herbal medicine-supportive treatment combination therapy was 30.76 days 


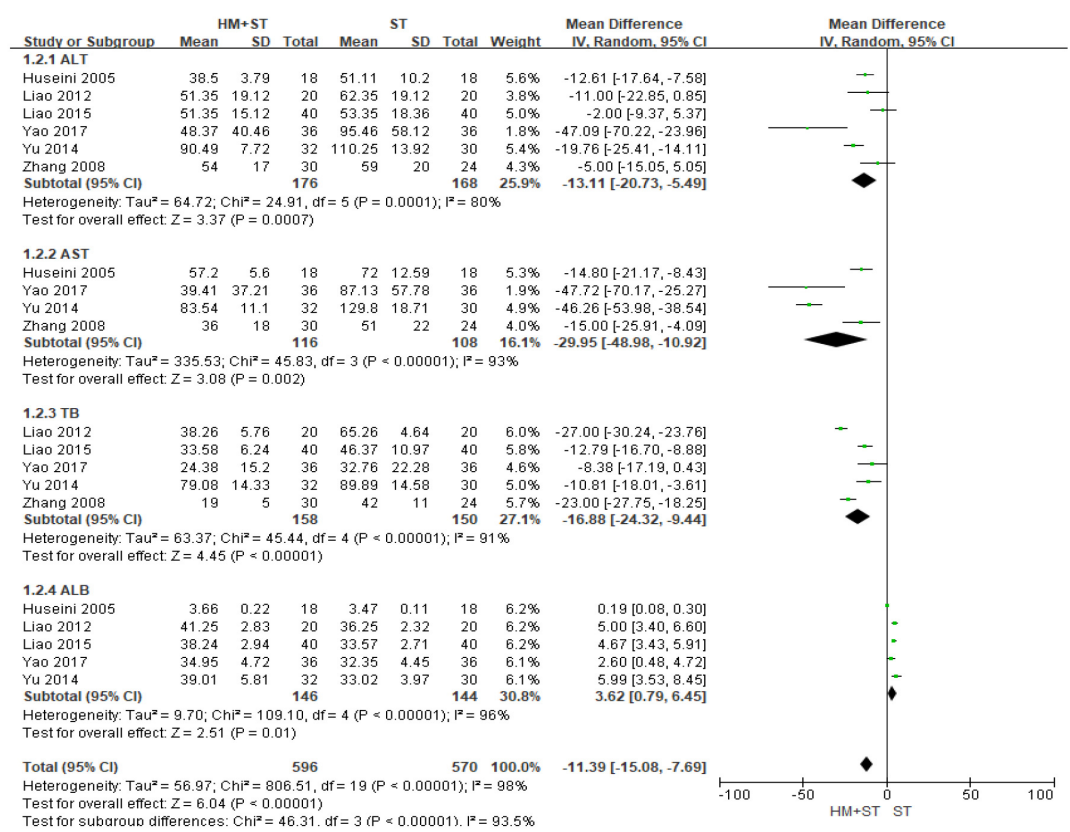

Fig. 3. Results of Meta-analysis for the Liver Function Test(HM+ST vs ST)

Abbreviations: HM, herbal medicine; ST, supportive treatment; ALT, alanine aminotransferase; AST, aspartate aminotransferase; TB, total bililirubin; ALB, albumin

Table 2. Composition of the herbal preparations used in treatment

\begin{tabular}{|c|c|c|}
\hline Study & Preparation name & Composition \\
\hline $\begin{array}{c}\text { Huseini }^{13} \\
(2005)\end{array}$ & Liv-52 & $\begin{array}{l}\text { Capparis spinosa, Cichorium Intybus } 65 \mathrm{mg} \text { respectively, Solanum nigrum, T.arjuna } 32 \mathrm{mg} \text {, Cassia } \\
\text { occitentalis, Achillea millefolium, Tamarix gallica } 16 \mathrm{mg} \text { respectively }\end{array}$ \\
\hline $\begin{array}{l}\mathrm{Liao}^{14} \\
(2012)\end{array}$ & herbal medicine & $\begin{array}{l}\text { Astragali Radix(黃芪), Alismatis Rhizoma(澤瀉), Atractylodis Rhizoma Alba(白术), Artemisiae } \\
\text { Capillaris Herba(茵蔯高), Poria Sclerotium(获苓), Salviae Miltiorrhizae Radix(丹參), Bupleuri } \\
\text { Radix(柴胡), Aurantii Fructus Immaturus(枳豰), Leonuri Herba(益母草), Pelodiscis Carapax(鰵甲) }\end{array}$ \\
\hline $\begin{array}{l}\text { Liao }^{15} \\
(2015)\end{array}$ & herbal medicine & compound formula \\
\hline $\begin{array}{l}\operatorname{Liu}^{16} \\
(2012)\end{array}$ & herbal medicine & 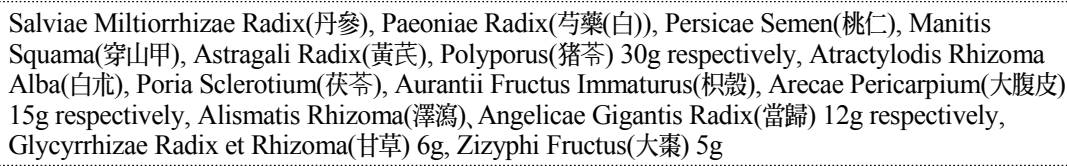 \\
\hline $\begin{array}{c}\operatorname{Liu}^{17} \\
(2017)\end{array}$ & herbal medicine & $\begin{array}{l}\text { Poria Sclerotium(获苓) 30g, Alismatis Rhizoma(澤鴧), Polyporus(猪苓), Atractylodis Rhizoma } \\
\text { Alba(白术) } 15 \mathrm{~g} \text { respectively, Cinnamomi Ramulu(桂枝) } 10 \mathrm{~g}\end{array}$ \\
\hline $\begin{array}{l}\mathrm{Qi}^{18} \\
(2017)\end{array}$ & herbal medicine & $\begin{array}{l}\text { Salviae Miltiorrhizae Radix(丹參) } 20 \mathrm{~g} \text {, Cnidii Rhizoma(川芎), Bupleuri Radix(柴胡), Leonuri } \\
\text { Herba(益母草), Poria Sclerotium(获苓), Citri Unshius Pericarpium Immaturus(青皮), Galli Gigeriae } \\
\text { Endothelium Corneum(鷄內金), Cyperi Rhizoma(香附子), Alismatis Rhizoma(澤瀉), Imperata } \\
\text { cylindrica(白茅根) } 15 \mathrm{~g} \text { respectively }\end{array}$ \\
\hline $\begin{array}{l}\text { Shen } \\
(2011)\end{array}$ & herbal medicine & $\begin{array}{l}\text { Astragali Radix(黃芪), Codonopsis Pilosulae Radix(黨參), Polyporus(猪苓), Salviae Miltiorrhizae } \\
\text { Radix(丹參) 30g respectively, Atractylodis Rhizoma Alba(白术), Poria Sclerotium(获苓), Polygoni } \\
\text { Cuspidati Rhizoma et Radix(虎杖根) 15g respectively, Sparganii Rhizoma(三稜), Curcumae } \\
\text { Rhizoma(莪术), Cnidii Rhizoma(川芎), Paeoniae Radix(苟藥(白)), Citri Unshius Pericarpium } \\
\text { Immaturus(青皮). Bupleuri Radix(柴胡), Cyperi Rhizoma(香附子), Curcumae Radix(鬱金), } \\
\text { Schisandrae Fructus(五味子) 10g respectively, Glycyrrhizae Radix et Rhizoma(甘草) 6g } \\
\text { compound formula }\end{array}$ \\
\hline
\end{tabular}


less than that of the supportive treatment stand -alone therapy. A high degree of heterogeneity of $100 \%$ was observed across the studies (Mean Difference $=-30.76,95 \%$ CI:-62.37 to 0.84 , $\mathrm{p}=0.06$, $\mathrm{I}^{2}=100 \%$, Fig. 4).

\section{5) Bias assessment}

Assessment of risk of bias was performed for the 13 articles included in this review using Cochrane risk of bias tool. With respect to random sequence generation domain, three $\operatorname{articles}^{13,21,23)}$ that used a table of random

Table 2. Composition of the herbal preparations used in treatment (Continued)

\begin{tabular}{|c|c|c|}
\hline Study & Preparation name & Composition \\
\hline $\begin{array}{l}\mathrm{Miao}^{20} \\
(2018)\end{array}$ & herbal medicine & 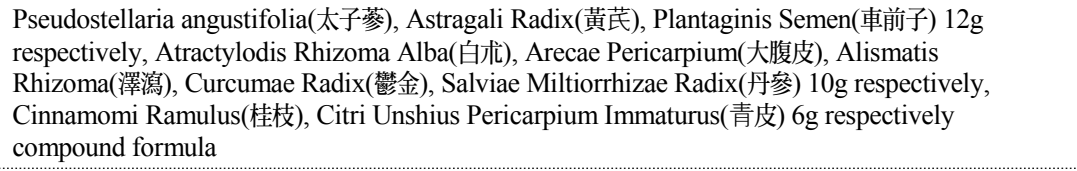 \\
\hline $\begin{array}{l}\mathrm{Yao}^{21} \\
(2009)\end{array}$ & herbal medicine & $\begin{array}{l}\text { Poria Sclerotium(获苓), Achyranthis Radix(牛膝), Aucklandiae Radix(木香), Bupleuri Radix(柴胡), } \\
\text { Amomi Fructus(砂仁) 30g respectively, Atractylodis Rhizoma Alba(白术), Polyporus(猪苓), } \\
\text { Alismatis Rhizoma(澤瀉), Salviae Miltiorrhizae Radix(丹參) } 15 \mathrm{~g} \text { respectively, Clematidis } \\
\text { Radix(威靈仙), Angelicae Gigantis Radix(當歸) } 10 \mathrm{~g} \text { respectively, Curcumae Longae Rhizoma(薑黃), } \\
\text { Scorpio(全蝎) 6g respectively, Glycyrrhizae Radix et Rhizoma(甘草) } 10 \mathrm{~g} \\
\text { compound formula }\end{array}$ \\
\hline $\begin{array}{c}\mathrm{Yao}^{22} \\
(2017)\end{array}$ & herbal medicine & $\begin{array}{l}\text { Astragali Radix(黃芪) 30g, Atractylodis Rhizoma Alba(白术), Salviae Miltiorrhizae Radix(丹參), } \\
\text { Imperata cylindrica(白茅根), Pelodiscis Carapax(鰵甲) } 20 \mathrm{~g} \text { respectively, Polyporus(猪苓), Alismatis } \\
\text { Rhizoma(澤瀉), Poria Sclerotium(获苓), Angelicae Gigantis Radix(當歸), Codonopsis Pilosulae } \\
\text { Radix(黨參), Arecae Pericarpium(大腹皮), Bupleuri Radix(柴胡) } 15 \mathrm{~g} \text { respectively, Plantaginis } \\
\text { Semen(車前子) } 12 \mathrm{~g} \text {, Curcumae Rhizoma(莪术), Glycyrrhizae Radix et Rhizoma(甘草) } 10 \mathrm{~g} \\
\text { respectively, Schisandrae Fructus(五味子), Cinnamomi Ramulus(桂枝) } 6 \mathrm{~g} \text { respectively } \\
\text { compound formula }\end{array}$ \\
\hline $\begin{array}{l}\mathrm{Yu}^{23} \\
(2014)\end{array}$ & herbal medicine & $\begin{array}{l}\text { Cistanchis Herba(肉蓯蓉), Salviae Miltiorrhizae Radix(丹參) } 20 \mathrm{~g} \text { respectively, Aconiti Lateralis } \\
\text { Radix Preparata(附子), Lycopi Herba(澤蘭), Angelicae Gigantis Radix(當歸) } 10 \mathrm{~g} \text { respectively, } \\
\text { Cinnamomi Ramulus(桂枝), Persicae Semen(桃仁) } 6 \mathrm{~g} \text { respectively, Zingiberis Rhizoma(乾葍) } \\
5 \mathrm{~g} \text {, Glycyrrhizae Radix et Rhizoma(甘草) } 4 \mathrm{~g} \\
\text { compound formula }\end{array}$ \\
\hline $\begin{array}{l}\text { Zhang }^{24} \\
(2008)\end{array}$ & herbal medicine & 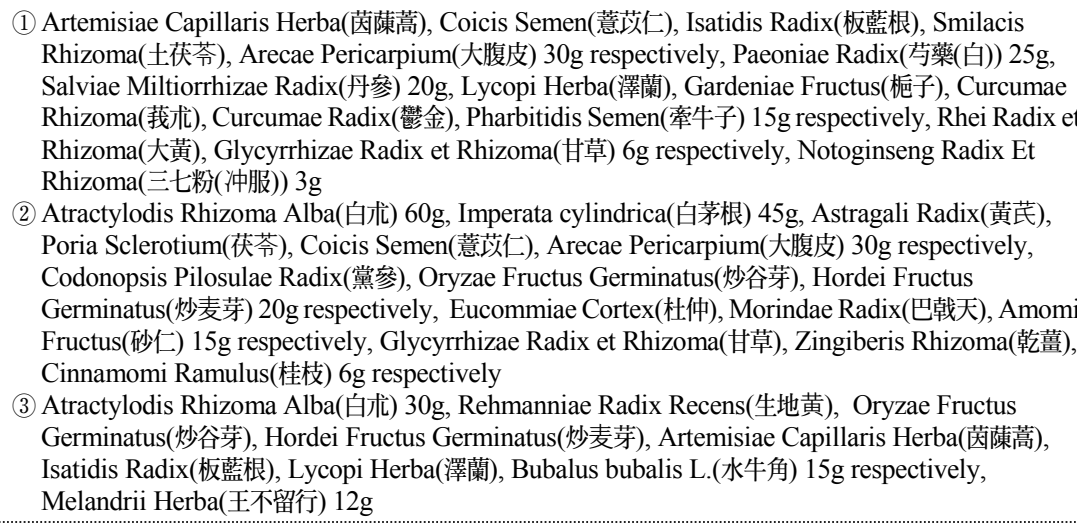 \\
\hline $\begin{array}{l}\text { Zhao }^{25} \\
(2016)\end{array}$ & herbal medicine & $\begin{array}{l}\text { Salviae Miltiorrhizae Radix(丹參), Artemisiae Capillaris Herba(茵蔯蒿), Poria Sclerotium(获苓), } \\
\text { Astragali Radix(黃芪) 20g respectively, Leonuri Herba(益母草), Pelodiscis Carapax(鱉甲), Ginseng } \\
\text { Radix(白参), Paeoniae Radix(苟藥(白)), Arecae Pericarpium(大腹皮) 15g respectively, Citri Unshius } \\
\text { Pericarpium(陳皮), Alismatis Rhizoma(澤㴼) 10g, Atractylodis Rhizoma Alba(白术) respecrively }\end{array}$ \\
\hline
\end{tabular}




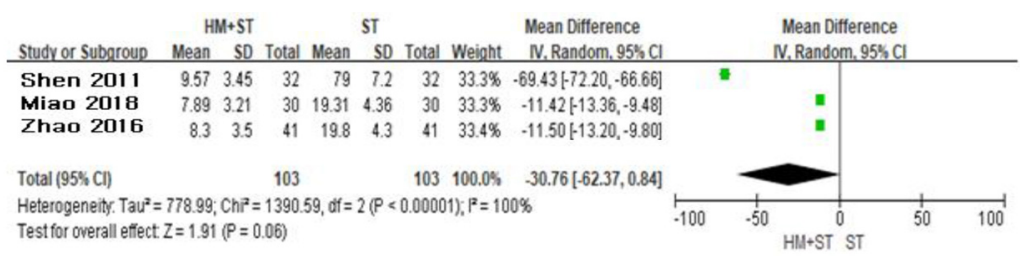

Fig. 4. Results of Meta-analysis for the Ascites Regression Time(HM+ST vs ST) Abbreviations: HM, herbal medicine; ST, supportive treatment;

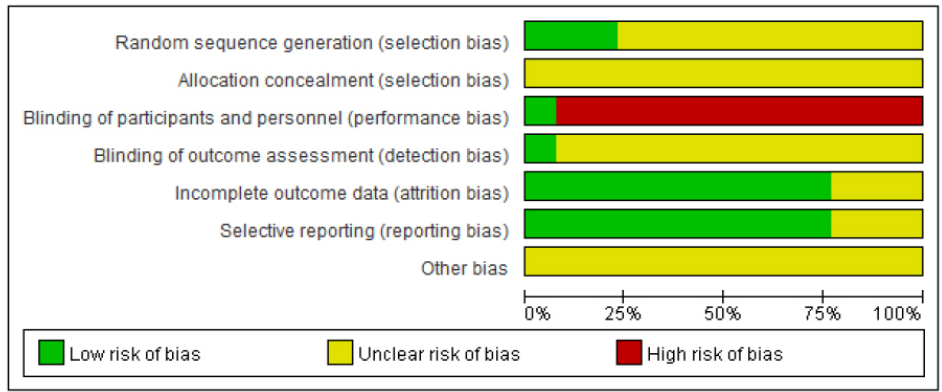

Fig 5. Risk of bias graph

numbers were assessed as having low risk, while the rest of the articles provided no details and were assessed as having unclear risk. All articles provided no details on allocation concealment, and therefore were assessed as having unclear risk. With respect to blinding of participants and personnel domain, one article ${ }^{13)}$ that used placebo was assessed as having low risk, while the rest of the articles were assessed as having high risk because blinding was deemed not possible due to the nature of intervention method that included herbal decoction. With respect to blinding of outcome assessor domain, one $\operatorname{article}^{13)}$ that reported using blinding was assessed as having low risk, while the rest of the articles provided no details and were assessed as having unclear risk. With respect to incomplete outcome data domain, 10 articles $^{13,16-17,19-25)}$ that reported missing values and confirmed no errors were assessed as having low risk, while the rest of the articles did not provide details and were assessed as having unclear risk. With respect to selective reporting domain, 10 articles $^{13-17,19-22,25)}$ that did not have study protocol but reported all pre-specified outcomes and all expected outcomes were assessed as having low risk, while the rest of the articles provided no details and were assessed as having unclear risk. With respect to other sources of bias domain, most articles did not provide sufficient information or evidence, and therefore all articles were assessed as having unclear risk (Fig. 5, Fig. 6).

\section{6) Publication bias}

Inspection of the funnel plot showed low risk of publication bias (Fig. 7) 


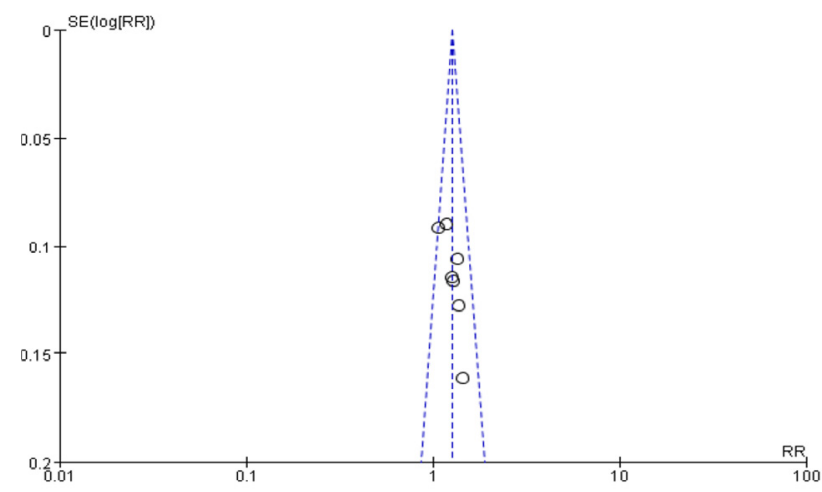

Fig. 6. Risk of bias summary

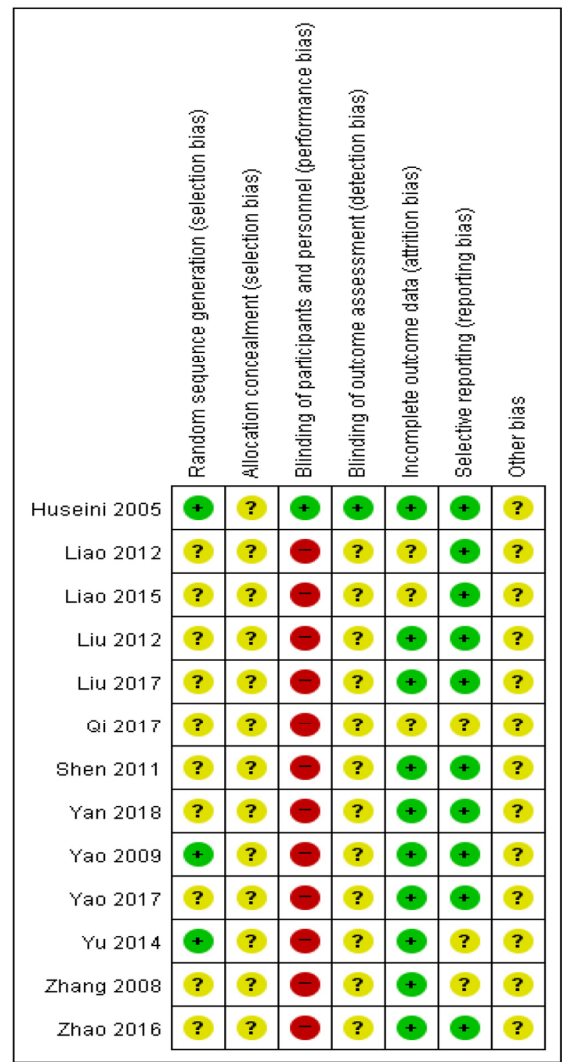

Fig. 7. Funnel plot for the outcome of effective rate (HM+ST vs ST)

Abbreviations: HM, herbal medicine; ST, supportive treatment;

\section{7) Safety}

Of the 13 studies included in this review, a total of three studies ${ }^{20,22,25)}$ reported adverse events. One study ${ }^{20)}$ one case of hyponatremia and one case of renal function occurred in the intervention group, whereas three cases of hyponatremia, three cases of renal dysfunction, and two cases of hepatic encephalopathy occurred in the control group, indicating that the safety of the intervention group was significantly higher than that of the control group $(p<0.05)$. In another study $^{22)}$, symptoms of headache and nausea occurred, but there was no significant difference between the intervention and control groups. In the third study ${ }^{25)}$, four cases of hyponatremia and one case of hepatic encephalopathy occurred in the intervention group, whereas 14 cases of hyponatremia, eight cases of renal dysfunction, and seven cases of hepatic encephalopathy occurred in the control group, indicating the safety of the intervention groups was significantly higher than that of the control group $(p<0.05)$ 


\section{Discussion and conclusions}

The present study performed a systematic review of RCT articles that provided oral herbal medicine treatment in patients with cirrhotic ascites. Through this review, we aimed to provide objective assessment of the effectiveness and applicability of oral herbal medicine treatment in patients with cirrhotic ascites. A total of 11 Korean and international databases were searched and 13 studies $^{13-25)}$ were ultimately selected for analysis.

Thirteen studies ${ }^{13-25)}$ included in the present study investigated the effect of herbal medicine -supportive treatment combination therapy on ascites in liver cirrhosis. These studies have been continuously published since 2005, with 12 studies $^{14-25)}$ conducted in China and one study ${ }^{13}$ published in Iran. From this, it can be speculated that there has been a continued interest in herbal medicine in the treatment of cirrhotic ascites, centering on China.

Of the outcome measures of 13 studies, effective rate, liver function test, and ascites regression time were included in the meta-analysis, which showed that the effective rate of herbal medicine-supportive treatment combination therapy was 1.27 times higher than that of supportive treatment alone, and the difference was statistically significant. The herbal medicine-supportive treatment combination therapy also had a significant effect on liver function test. Although ascites regression time of the herbal medicine -supportive treatment combination therapy was 30.76 days less than that of supportive treatment alone, the difference was not statistically significant. Despite the fact that the difference in ascites regression time was not significant, we believe that use of herbal medicine-supportive treatment combination therapy will be of value in the treatment of cirrhotic ascites.

Risk of bias assessment of the 13 articles included in the systematic review revealed high performance bias. We believe that this was due to the fact that blinding was not possible because of the nature of intervention method that included herbal decoction. Most studies did not have detailed report on bias assessment, which made it difficult to assess bias except for performance bias. We believe that future studies that address this issue will provide stronger evidence.

There is a limitation in that the majority of the studies included in the present study did not categorize or take into consideration the degree of ascites and syndrome differentiation despite the fact that treatment method and course of disease may vary depending on those factors. Only one study $^{13)}$ classified the degree of ascites as without, mild, moderate, or severe and assessed the proportion after 6 months of administration of herbal medicine intervention. Two studies ${ }^{14,15)}$ reported the degree of ascites in subjects participating in the experiment by classifying it as mild, moderate, severe, or moderate volume and large volume, but these were not reflected when reporting the study results. The other ten studies $^{16-25)}$ did not report the degree of ascites of the participants. Furthermore, despite the various causes of ascites, only two studies ${ }^{15,24)}$ provided prescription according to syndrome differentiation. Three studies ${ }^{13,16-17)}$ used one prescription, without taking into account syndrome differentiation, and 
seven studies ${ }^{14,18-23,25)}$ added or subtracted herbs from the basic formula according to the accompanying symptoms. As such, most studies provided the same prescription without taking into account syndrome differentiation. In addition, it is disappointing that even the study ${ }^{13)}$ that reported the degree of ascites and performed comparative evaluation used a general prescription without providing different treatment methods according to the degree of ascites. In the future, more significant conclusions may be drawn if appropriate prescriptions are given according to the degree of ascites and syndrome differentiation.

The present study performed a systematic review and meta-analysis of published RCTs in order to investigate the effect of oral herbal medicine treatment in patients with cirrhotic ascites. The results showed that oral herbal medicine-supportive treatment combination therapy was significantly more effective in effective rate and liver function test than supportive treatment alone, while no significant difference was found in ascites regression time. Through this study, we demonstrated that oral herbal medicine-supportive treatment combination therapy is significantly more effective than supportive treatment alone in treating patients with cirrhotic ascites. We believe that there is a need to establish stronger evidence through future clinical trials on herbal medicine in the treatment of cirrhotic ascites that addresses the above limitations.

\section{Acknowledgement}

This study was supported by the 2018 National Research Foundation of Korea grant funded by the Korean government (Ministry of Science and ICT) (No. 2018R1A5A2025272).

\section{References}

1. Korean Statistical Information Service (KOSIS) Annual report on the cause of death statistics 2017 [Internet] Daejeon: Statistics Korea; [cited 2021 Jul 04]. Available from: $\mathrm{http} / / / \mathrm{kosis} . \mathrm{kr} / \mathrm{search} / \mathrm{search}$. do?query $=\% \mathrm{EC} \%$ $82 \%$ AC $\%$ EB $\%$ A7\% $\%$ D $\%$ EC $\% 9 B \% 90 \%$ EC $\% 9$ $\mathrm{D} \% \mathrm{~B} 8$.

2. Bacon BR. Cirrhosis and Its complications. In: Kasper, DL, Fauci AS, Hauser S, Longo D, Jameson JL \& Loscalzo J. Harrison's Principles of Internal Medicine. 19th ed. NewYork: McGraw-Hill. 2017:2943-4.

3. Kim, K.A. (2009). Management of the Patients with Liver Cirrhosis. Clinical and Molecular Hepatology. 15(3s), 276-80.

4. Bianchi, G., Marchesini, G., Nicolino, F., Graziani, R., Sgarbi, D., Loguercio, C., et al. (2005). Psychological status and depression in patients with liver cirrhosis. Digestive and liver disease : official journal of the Italian Society of Gastroenterology and the Italian Association for the Study of the Liver, 37(8), 593-600. https://doi.org/10.1016/j.dld.2005.01.020

5. Korean Association for the Study of the Liver (KASL) (2018). KASL clinical practice guidelines for liver cirrhosis: Ascites and related complications. Clinical and molecular hepatology, 24(3), 230-277. https://doi.org/10. 3350/cmh.2018.1005

6. D'Amico, G., Garcia-Tsao, G., \& Pagliaro, L. (2006). Natural history and prognostic indicators 
of survival in cirrhosis: a systematic review of 118 studies. Journal of hepatology, 44(1), 217-231. https://doi.org/10.1016/j.jhep.2005.10.013

7. Professor Group of Korean Internal Medicine of Liver system. Korean Internal Medicine of Liver system. 6th ed. Seoul: Nado. 2015: 327-54.

8. Lee, C.H., Kim, B.S., Kim, K.S., Kwak, M.A., \& Kim, S.M., (2018). Effects of Electroacupuncture on the Muscle Cramps of Liver Cirrhosis Patients: A Randomized Controlled Study. The Journal of Internal Korean Medicine. 39(4). 511-519. https://doi.org/ 10.22246/jikm.2018.39.4.511

9. Bae, J., Joo, S., An, S., Jang, E., Kim, Y., \& Lee, J. (2018). A Case Study of Two Alcoholic Liver Cirrhosis Patients. The Journal of Internal Korean Medicine, 39(2), 176-183. https://doi.org/10.22246/jikm.2018. 39.2.176

10. Kim, E., Bae, I., \& Shin, G. (2017). A Case Report of Dyspepsia in a Patient with Liver Cirrhosis and Pancytopenia. The Journal of Internal Korean Medicine, 38(5), 592-599. https://doi.org/10.22246/jikm.2017.38.5.592

11. Kang, K.W., Lee, J.H. (2016). A Case of Alcoholic Liver Cirrhosis Treated with Injinoryeong-san. The Journal of Internal Korean Medicine, 37(1), 135-142.

12. Kim, S. Y., Park, J. E., Seo, H. J., Lee, Y. J., Jang, B. H., Son, H. J., et al. (2011). NECA's guidance for undertaking systematic reviews and meta-analyses for intervention. Seoul: National evidence-based healthcare collaborating agency.

13. Huseini, H. F., Alavian, S. M., Heshmat, R., Heydari, M. R., \& Abolmaali, K. (2005).
The efficacy of Liv-52 on liver cirrhotic patients: a randomized, double-blind, placebo -controlled first approach. Phytomedicine : international journal of phytotherapy and phytopharmacology, 12(9), 619-624. https://doi. org/10.1016/j.phymed.2004.10.003

14. Liao, W. Z., \& Zeng, Y. S. (2012). Clinical Observation of Self-designed Chinese Medicinal Boiling Agent in Treatment of Hepatocirrhosis ascites(自拟中药者散剂治疗 肝硬化腹水的临床观察). Chinese Journal of General Practice(中华全科医学)，10(3)，432 -433. http://www.cqvip.com/qk/87341a/201203/ 41075263.html

15. Liao, W. Z. (2015). Chinese Medicine Powder for Boiling and Honeyed Pill Combined with Antiviral Medicine in the Treatment of Hepatitis B Liver Cirrhosis Ascites(中药煮散, 蜜丸联合抗病毒药物治疗乙 肝肝硬化腹水). Chinese Medicine Modern Distance Education of China(中国中医药现 代远程教育)，(24)，33-35. http://www.cqvip. com/qk/87077x/201524/667845150.html

16. Liu, X. W. (2012). Clinical analysis of 67 cases of liver cirrhosis peritoneum with Chinese medicine(中药辅治肝硬化腹水 67 例 临床分析). Chin J of Clinical Rational Drug Use(临床合理用药杂志)，5(34)， 74-75. http://www.cqvip.com/qk/88922x/201234/439 07073.html

17. Liu, X. M., \& Li, H. Q. (2017). Observation on the Effect of Traditional Chinese Medicine in Hepatocirrhosis with Wuling Powder Combined with Peritoneal Acupuncture (中药 经方五苓散联合腹针疗法治疗肝硬化腹水疗效 观察). Digest of the World Core Medical 
Journals. Clinical Neurology(世界最新医学信 息文摘(电子版), (33), 108-113. https://www. cnki.com.cn/Article/CJFDTotal-WMIA20173 3079.htm

18. Qi, Y. (2017). Clinical Effect of Traditional Chinese Medicine in the Treatment of Liver Cirrhosis Ascites(中医中药治疗肝硬化腹水的 临床效果观察). China Continuing Medical Education(中国继续医学教育), 9(33), 105-106. http://www.cqvip.com/QK/71296X/201733/67 4355917.html

19) Shen, F. M., Wang, C. Y., \& Song, C. Y. (2011). Treatment of Hepatiosclerotic ascites with Western medicine in 32 cases(健脾利水 中药配合西药治疗肝硬化腹水 32 例). Shaanxi Journal of Traditional Chinese Medicine(陕 西中医), 32(9), 1110-1111. http://www.cqvip. com/qk/94970x/201109/39302503.html

20. Miao, S. H, Wu, Z. W., \& Zhu, H. Y. (2018). Clinical analysis of spleen-strengthening medicine with western medicine in the treatment of cirrhosis of liver ascites(健脾利 水中药配合西药治疗肝硬化腹水的临床疗效分 析). Journal of Contemporary Clinical Medicine(当代临床医幵)，31(2)，3752-3753. http://www.cqvip.com/qk/96520a/201802/700 0516632.html

21. Yao, S. Y. (2009). The study of traditional Chinese medicine cures the ascites of liver cirrhosis(中药方剂治疗肝硬化腹水初探). Journal of Liaoning University of Traditional Chinese Medicine (辽宁中医药大学学报), 11(5), 102-103. https://en.cnki.com.cn/Article _en/CJFDTotal-LZXB200905056.htm

22. Yao, R. (2017). Clinical Observation on Treatment of Hepatitis B Hepatopancreatic ascites with Traditional Chinese Medicines and Western Medicines(中药消臌汤联合西药 治疗乙肝肝硬化腹水的临床观察). Journal of Aerospace Medicine(航空航天医学杂志), 28(8), 1007-1009. http://www.cqvip.com/qk/90537a/ 201708/673295737.html

23. Yu X.F., Lin, L. \& Song, Y. (2014). Clinical Observation of Traditional Chinese Medicine by Many Ways and Western Medicine Treating Liver Cirrhosis Ascites. Journal of Emergency in Traditional Chinese Medicine, 23(5), 1692-1694. http://www.cqvip.com/qk/ 89565x/201401/48396693.html

24. Zhang, B. H. (2008). Curative Effect on Diuretic and Compound Chinese Medicine for 30 Cases of Hepatitis Cirrhosis Ascites(利 尿剂联合复方中药治疗肝硬化腹水 30 例疗效观 察). Modern Diagnosis and Treatment(中国 现代医生), 46(4), 5-7. http://www.cqvip.com/ qk/60066a/2008004/26697578.html

25. Zhao, Z. S., Chen, H. B., \& Lin, Z. P. (2016). Clinical Effect Observation of Treating Liver Cirrhosis Ascites with Traditional Chinese Medicine Combined with Western Medicine. Modern Diagnosis and Treatment, 27(6), 1015-1017.

\section{ORCID}

Seungmo Kim https://orcid.org/0000-0002-9962-3405

Yuri Lee https://orcid.org/0000-0002-2435-4650 Nakyung Cho https://orcid.org/0000-0002-3555-2011 Hongsik Choi https://orcid.org/0000-0001-8586-8519 Kyungsoon Kim https://orcid.org/0000-0002-6835-2075 